\title{
Association d'organismes de type mycoplasmes avec le dépérissement mortel des cocotiers de Grand-Lahou en Côte d'Ivoire
}

\author{
Yao A. AMENAN ${ }^{1}$, Agneroh T. ATCHAM ${ }^{2 *}$, J. POHE ${ }^{2}$, M. A. D'ALMEIDA ${ }^{3}$ et \\ P. ZAMA $^{4}$ \\ ${ }^{I}$ Ministère de l'Agriculture 01 B.P 4054 Abidjan, Côte d'Ivoire. \\ ${ }^{2}$ Institut National Polytechnique Félix Houphouët-Boigny-Département Agriculture et Ressources Animales- \\ Laboratoire de Phytopathologie et Biologie Végétale B.P. 1313 Yamoussoukro, Côte d'Ivoire. \\ ${ }^{3}$ Institut Pasteur-Centre GERME 17 B.P. 332 Abidjan, Côte d'Ivoire. \\ ${ }^{4}$ Société Ivoirienne de Coco Râpé (SICOR) 04 B.P. 973 Abidjan, Côte d'Ivoire. \\ *Corresponding author, E-mail: tatchamagneroh@yahoo.fr
}

\section{RESUME}

Depuis 1995, s'observe dans la plantation industrielle de cocotiers de la SICOR un dépérissement mortel du cocotier. La présente étude, en complément aux problèmes hydriques et pédologiques identifiés, est fondée sur les symptômes, l'épidémiologie et l'étiologie. Afin d'appréhender l'épidémiologie, la prospection générale de la plantation a montré qu'en dehors de ce dépérissement, il existe une chute des noix immatures de cocotiers non dépérissants. Les recherches au laboratoire ont abouti au Phytophthora katsurae qui en est le responsable. En ce qui concerne les recherches sur le dépérissement, les investigations sur les champignons et les bactéries ont été vaines. Ainsi, l'observation au microscope électronique de fragments d'inflorescences et de feuilles d'arbres dépérissants a mis en évidence, par rapport aux témoins sains prélevés dans une zone saine, des particules de formes arrondies de types mycoplasmes. Une comparaison avec les autres maladies à jaunisses du cocotier a montré de nombreuses analogies avec les maladies de Kaincopé au Togo, de Kribi au Cameroun et du Cap Saint Paul au Ghana. De nouvelles recherches pratiques sont prévues: l'identification de l'insecte vecteur par des essais de transmission, son lieu de ponte, l'identification par sérologie et polymerase chain reaction (PCR) du phytoplasme et les traitements aux antibiotiques.

(C) 2012 International Formulae Group. All rights reserved.

Mots clés: Cocotiers dépérissants, Phytophthora katsurae, maladie à jaunisse, microscope électronique, phytoplasme.

\section{INTRODUCTION}

Le cocotier (Cocos nucifera L.) est une culture importante dans le littoral de la Côte d'Ivoire (Assa et al., 2006 ; Centre National de Recherche Agronomique (CNRA), 2006). Il procure aux communautés vivant sur la côte de la nourriture par ses noix riches en huile et en lait de coco. Il est aussi utilisé comme provende, matériau de construction, combustible, fibre en filature et tissage et substrat dans les pots de pépinières d'hévéa et de bananier. Il assure un revenu non seulement aux producteurs dans l'exploitation de l'huile de coprah, du coco râpé et d'autres produits gras du cocotier mais également des opportunités de travail.

Le verger ivoirien de cocotiers autrefois géré par les ex-sociétés d'Etat 
SODEPALM (Société de Développement du Palmier) et PALMINDUSTRIE (Industrie du Palmier) atteint 50000 ha répartis en plantations villageoises (30000 ha) et en plantations industrielles (20000 ha) (CNRA, 2006). Des hybrides issus du croisement entre le Grand Ouest Africain (GOA) et les Nains avaient fait leur apparition faisant passer la production de $500 \mathrm{~kg} / \mathrm{ha}$ de coprah avec le GOA à 5-6 $\mathrm{t}$ avec les hybrides. C'est dans le cadre de la privatisation des sociétés d'Etat que la Société Ivoirienne de Coco Râpé (SICOR) avait acheté en 1996 environ 12000 ha de plantations industrielles situées à GrandLahou (4930 ha), Glike (5190 ha), et Jacqueville-Boulay (2119 ha) pour la transformation de sa production en coco râpé.

Avec son usine installée à Jacqueville, la SICOR produit $11 \%$ du coco râpé mondial et constitue le seul opérateur du continent africain. Afin de conquérir de nouveaux marchés grâce à l'excellente qualité du coco râpé produit, la SICOR demande un ravitaillement de manière quantitative et qualitative de son usine en noix. Les objectifs de la SICOR pourraient facilement être optimisés si les cocoteraies ne connaissaient pas de problèmes pathologiques. En plus de la chute des noix immatures et de la pourriture du cœur du cocotier dues à Phytophthora katsurae, s'était ajouté à Grand-Lahou en 1995 un autre fléau qui est le dépérissement mortel des cocotiers (Anonyme, 1995). Les observations de l'équipe phytosanitaire de la SICOR avaient permis d'estimer pour le seul mois de Janvier 1997, le nombre d'arbres morts à l'équivalent d'un hectare à un hectare et demi selon les parcelles (Anonyme, 1997). Ces nombres étaient passés du simple au double après 3 mois selon les mêmes observations.

L'augmentation sans cesse des cas de mortalité dans les plantations industrielles et villageoises avait fait naître des inquiétudes au sein du service de la production de la SICOR et créé comme impératif une activité de recherche. Les premières recherches étiologiques avaient milité en faveur du stress hydrique accompagné par une mauvaise qualité du sol de la cocoteraie à savoir la carence magnésienne (Anonyme, 1997 ; Yao, 1997). Cependant, elles suggéraient la prospection d'autres voies au cas où les plants reconnus comme dépérissants en début de saisons des pluies ne reprendraient pas jusqu'à la fin de celles-ci. En raison de la persistance du dépérissement dans certaines parcelles où les symptômes devraient disparaître avec les pluies et son évolution actuelle sur des centaines d'hectares, les travaux de recherche ont repris en se basant sur les agents biotiques responsables des maladies sur le cocotier. Un accent particulier a été mis sur les similitudes avec les maladies à jaunisse.

Des dépérissements mortels similaires ont été identifiés chez le cocotier en Afrique au Togo (Kaincopé), au Ghana (Cape Saint Paul wilt), au Nigeria (bronze leaf ou Awka wilt), au Cameroun (Kribi), en Tanzanie, Kenya et Mozambique (Lethal Disease) (Bachy et Hoestra, 1958 ; Dollet et al., 1977 ; Dery et al., 1996 ; Dollet et al., 2008, 2011 ). Les recherches dans ces pays ont montré qu'il s'agissait de la maladie du jaunissement mortel du cocotier due à un microorganisme de type phytoplasme. En Floride, elle est transmise d'arbre à arbre par un insecte vecteur Myndus crudus Van Duzee, de 1'ordre des Homoptères et de la famille des Cixiidae. En Afrique le vecteur demeure inconnu (Philippe et al., 2007, 2009). Dans le cas de la Côte d'Ivoire, de tels dépérissements n'ont pas encore été identifiés. L'objectif de cette étude est de déterminer à partir des enquêtes phytosanitaires et des observations au microscope de tissus malades et du sol prélevé dans les parcelles malades les causes de ce fléau.

\section{MATERIEL ET METHODES \\ Enquêtes phytosanitaires}

Elles ont consisté en des passages bimensuels dans la cocoteraie de GrandLahou au cours desquels sont dénombrés dans 
les parcelles préalablement choisies à la suite de la visite générale ayant situé des cas de dépérissement :

- des arbres morts;

- des arbres dépérissants;

- des noix pourries issues de cocotiers dépérissants ou non.

L'abattage et le débourrage et/ou le concassage des noix pourries s'avéraient souvent nécessaires pour la description des symptômes. La dispersion du dépérissement dans la cocoteraie a été approfondie grâce à une visite de $5 \%$ des premières parcelles dénombrées par l'équipe phytosanitaire de la SICOR après un tirage statistique sans remise. Elle a pour objectif de savoir l'homogénéité des cas observés. Les huit parcelles (B15, F25, A1l, A1, F27, B14, B18, D5) retenues par rapport à la carte sanitaire de la cocoteraie (Yao, 1997) couvraient 175 ha. Elles constituaient un échantillon représentatif selon Taffin et Rognon (1991). Au cours de ces passages, les observations avaient porté sur la description des symptômes et l'évolution de l'état sanitaire des arbres dépérissants marqués à la peinture bleue en début de la grande saison des pluies. Dix cocotiers dépérissants dispersés dans les parcelles avaient été également suivis lors de la saison pluvieuse pendant 3 mois.

\section{Analyses mycologiques}

Ces analyses ont porté sur des parties d'organes pourries de cocotiers et des échantillons de sols prélevés dans les parcelles infectées et apparemment saines. Ces dernières jouent le rôle de témoin.

\section{Matériel végétal}

Les échantillons prélevés après abattage de trois cocotiers dépérissants ayant déjà perdu leurs fruits à l'aide d'une tronçonneuse, comportaient des parties de cœur, des fragments de bas de rachis, des pédoncules d'inflorescences, des bases de palme non ouverte et des noix tombées.

\section{Milieu de culture}

Dans la tentative d'explication de l'origine du dépérissement, des milieux de culture gélosés à $20 \mathrm{~g} / \mathrm{l}$ à base d'extrait de pomme de terre (Pomme de terre-DextroseAgar) ont servi à l'incubation des échantillons et à l'isolement des espèces fongiques. Ces milieux n'ont pas été supplémentés en antibiotique pour pouvoir détecter les colonies bactériennes.

Des fractions de sol ont aussi été utilisées pour y étudier les champignons telluriques. Il s'agit du sol issu de parcelles malades et de parcelles apparemment saines (B21 et D22).

\section{Techniques d'isolement}

Pour les analyses au laboratoire, la méthode d'Ulster comme décrite par Molard et Chagnier (1989) ou méthode directe a été utilisée pour le matériel végétal et les méthodes de dilution-suspension et du soil plate pour le sol.

\section{Identification des phytoplasmes Matériel végétal}

Les analyses ont porté sur des parties de plantes malades et saines prélevées respectivement à Grand-Lahou et à Adiopodoumé. Les dernières servaient de témoins. Cette zone n'est pas encore touchée par le dépérissement du cocotier qui sévit à Grand-Lahou. Les échantillons à analyser étaient composés:

- d'inflorescences encore enfermées dans leur spathe de plants malades et sains;

- de jeunes feuilles non ouvertes ou flèches, feuilles âgées jaunies pour les malades et vertes pour le témoin;

- de jeunes racines.

\section{Préparation des échantillons}

La préparation des échantillons s'est faite selon la méthode décrite par Dollet et Giannotti (1976). Compte tenu de la proximité de la plantation d'Adiopodoumé au laboratoire de microscopie électronique, tous les travaux ont été effectués au laboratoire du GERME (Groupe d'Etude et de Recherche en 
Microscopie Electronique) de l'Institut Pasteur d'Abidjan. Ainsi, les échantillons à analyser ont été découpés en petits morceaux d'environ 2 à $4 \mathrm{~mm}$ de longueur à l'aide d'une lame rasoir et mis dans des piluliers. Ils ont été fixés à $4{ }^{\circ} \mathrm{C}$ dans le glutaraldéhyde à $4 \%$ tamponné à pH 7.2 avec le cacodylate de sodium 0.1 M. Après un rinçage dans la solution tampon, a suivi une post-fixation dans une solution de tétraoxyde d'osmium à $1 \%$ toujours en milieu tamponné à $4{ }^{\circ} \mathrm{C}$. Un deuxième rinçage est intervenu et, les échantillons ont été déshydratés dans des bains d'acétone à concentration croissante (50\%, 70\%, 90\%, 100\%).

Les échantillons déshydratés ont été imprégnés avec la solution de résine 'épon' diluée à l'acétone selon les proportions suivantes: $1 / 4$ de résine pour 3/4 d'acétone, $1 / 2$ de résine pour $1 / 2$ d'acétone, $3 / 4$ de résine pour $1 / 4$ d'acétone. Les pièces à analyser qui sortaient de la troisième composition après 17 $\mathrm{h}$ ont été plongées dans une solution pure de résine pendant $2 \mathrm{~h}$. Le matériel était ensuite inclus pendant trois jours à l'étuve réglée à 70 ${ }^{\circ} \mathrm{C}$ dans un moule. Mais avant de disposer les échantillons dans le moule et permettre une bonne adhérence des échantillons au fond des puits, une goutte du milieu d'inclusion était mise dans chaque puits de celui-ci. L'ensemble a été disposé à l'étuve réglée à 50 ${ }^{\circ} \mathrm{C}$ pendant $2 \mathrm{~h}$ pour amorcé la solidification.

Les coupes des blocs ont été réalisées à l'ultramicrotome à l'aide de deux couteaux. L'un en verre permettait de lisser la surface de coupe et de faire les coupes semifines observables sous microscope optique après coloration dans du bleu de toluidine et montage entre lame et lamelle. L'autre en diamant était utilisé pour effectuer les coupes ultrafines. Ces dernières ont été montées sur des grilles en cuivre circulaires de $3 \mathrm{~mm}$ de diamètre. Elles ont été contrastées dans une solution d'acétate d'uranyle pendant $5 \mathrm{mn}$ puis, dans une solution de citrate de plomb pendant $3 \mathrm{mn}$. Elles ont été enfin observées au microscope électronique à transmission de type ZEISS EM 900 du laboratoire du GERME à Abidjan.

\section{Inventaire des adventices de la plantation}

Des échantillons d'adventices de la cocoteraie de Grand-Lahou ont été acheminés au Laboratoire de Phytopathologie et Biologie Végétale de l'INP-HB et identifiés à l'aide des clés de détermination.

\section{RESULTATS \\ Identification des adventices}

La population de mauvaises herbes est constituée essentiellement de Cypéracées, d'Astéracées notamment Chromolaena odorata, de Commelinacées, de Graminées et de plantes vivaces (Tableau 1).

\section{Identification des cas de pathologies}

Une prospection de la cocoteraie a permis de remarquer qu'en dehors des problèmes pathologiques manifestés par le dépérissement mortel des cocotiers, des attaques d'insectes notamment des cochenilles, des Aceria et des Oryctes, ont été observées. Par ailleurs, dans certaines parcelles, une chute abondante de noix immatures s'opérait sur les cocotiers non dépérissants.

Maladie 1: chute des noix immatures de cocotiers non dépérissants

Symptômes: Sur les cocotiers qui présentaient la maladie 1, le seul fait marquant était la chute des noix immatures. Sur ces noix, on a observé des taches sous forme de plages qui étaient d'abord translucides et étaient devenues brunes par la suite (Figure 1). En évoluant, le centre de la tache devenait jaunâtre avec un liséré brun et une marge translucide. Dans la bourre, la pourriture observée était brune avec un liséré brun-clair sur le front de croissance.

Localisation: Cette pathologie a été observée dans les parcelles autres que celles qui étaient dépérissantes à savoir D5, D4, C4, C3, D24 à D27, E24 à E27. Elle s'étendait sur une superficie totale de 275 ha. Il est à noter 
que cette chute de noix ne se manifestait que sur les cocotiers hybrides, car, les parcelles D5, D4, C3, C4 signalées comme étant plantées avec le GOA, n'étaient en fait que des parcelles peuplées d'un mélange de variétés hybrides et de GOA.

Isolements: Les isolements sur les noix issues de cocotiers non dépérissants ont permis d'observer des mycéliums, des zygotes, des chlamydospores et des sporocystes (Figure 2) caractérisant les Phycomycètes. Les symptômes et les organes observés étaient ceux de la pourriture des noix du cocotier comme décrite par Pohé (1996). Comme le GOA résiste à la chute des noix due au $P$. katsurae (De Francqueville et al., 1989) l'intensité de celle-ci n'était pas beaucoup prononcée dans ces parcelles de mélange que dans les parcelles du D24 au D27 et du E24 au E27 qui étaient uniquement des hybrides.

\section{Maladie 2 : dépérissement mortel}

Symptômes: Le dépérissement s'est manifesté à son début par la chute des noix immatures. Cette chute des noix a commencé dans certains cas sur un seul côté de l'arbre et, parfois certaines noix restaient séchées sur le cocotier. Il s'agissait des noix proches de la maturité. Les symptômes du dépérissement sont présentés dans les Figures 3a, 3b, 3c et 3d. Les fruits tombés présentaient une pourriture noirâtre qui débutait du côté proximal. Une coupe de ceux-ci a révélé que certains avaient leur amande formée pendant que d'autres venaient à peine de l'amorcer. Ces amandes se détachaient facilement de l'endocarpe et elles dégageaient une forte odeur. La chute des noix était suivie par un jaunissement chlorotique des feuilles les plus basses. Celles-ci finissaient par brunir et tomber. Le jaunissement progressait vers les autres feuilles de la couronne foliaire, et, tout l'arbre devenait jaune en l'espace de trois mois. Les Figures $4 \mathrm{a}, 4 \mathrm{~b}$ et $4 \mathrm{c}$ présentent les symptômes de jaunissement sur les cocotiers dépérissants. Parallèlement, dans les inflorescences, les fleurs noircissaient et même dans les spathes non encore ouvertes (Figures 5a et 5b).

L'abattage et la dissection de plusieurs arbres à différents stades du dépérissement ont montré une pourriture molle et humide qui avait débuté à la base de la flèche (Figure 6). Cette pourriture s'était installée après les symptômes de jaunissement. La pourriture naissante a évolué vers le coeur et, au stade final, la couronne a flétri (Figure 7a), basculé et est tombée (Figure 7b).

\section{Localisation et dispersion des cas de dépérissement \\ Intensité de la mortalité par variété}

Parmi les variétés existant sur la plantation et leurs cas de mortalité et grâce à la base de données relatives au comptage bimensuel de plants morts et dépérissants (Yao, 1997), les hybrides sont plus soumis à cette mortalité que les GOA (Tableau 2).

A l'intérieur de cette même variété, les cultures de 1974 (Tableau 3) affichent le plus grand nombre de cas de mortalité (1555 sur un total de 2289 soit un pourcentage de $67.93 \%$ ).

$\mathrm{Au} \mathrm{vu} \mathrm{du}$ pourcentage de mortalité enregistré au B21 et au B22, nous pouvons retenir ces deux parcelles comme les plus dépérissantes. Par ailleurs, elles sont situées en bordure d'une forêt qui les sépare de $500 \mathrm{~m}$ de la lagune qui borde la plantation.

\section{Dispersion du dépérissement dans la cocoteraie}

La visite des $5 \%$ des parcelles supposées malades a donné les résultats inscrits dans le Tableau 4.

$\mathrm{Au}$ regard du Tableau 4, nous remarquons que sur les huit parcelles tirées au sort seulement trois d'entre elles manifestent le dépérissement décrit précédemment, soit une proportion de $3 / 8$.

Il est à noter que dans une parcelle soumise au dépérissement, les cocotiers morts et dépérissants se retrouvent en petits foyers dispersés dans celle-ci. Cependant, les foyers sont plus grands autour du foyer initial. Ceci 
peut suggérer l'existence d'un agent biotique responsable de la dispersion du dépérissement.

La parcelle A1 qui est séparée du B21 et du B22 d'environ $15 \mathrm{~km}$ manifeste le dépérissement. Il est intéressant de retenir que celle-ci contiguë à une plantation villageoise plantée avec le même matériel végétal, est aussi dans une phase de dépérissement. C'est pour dire que le fléau ne se limite pas seulement à la plantation de la SICOR. C'est pourquoi il est intéressant d'apprécier l'impact de ce dépérissement sur les parcelles concernées.

\section{Evolution du dépérissement}

L'évolution de l'infection au B21 et au B22 (Tableau 5) montre que les cas de dépérissement sont plus prononcés dans la période de Mars à Août qui englobe en fait la saison pluvieuse.

Nous en déduisons que la saison pluvieuse aurait un effet amplificateur sur cette maladie et que, la parcelle B22 est plus infectée que B2l même si le foyer a débuté dans ce dernier. Certainement, la situation de celle-ci par rapport à la forêt jouerait un rôle dans la progression de cette maladie

Le suivi des plants a aussi montré que mis à part les plants du D30 qui ont tous repris, tous les autres retenus dans les deux autres parcelles ont continué à dépérir. Par ailleurs, les symptômes de cassure des palmes à la base du rachis, caractéristiques du stress hydrique ne sont observés que dans la parcelle D30.

Nous pouvons tirer une première conclusion selon laquelle il ne s'agirait pas du même cas dans toutes les parcelles. Les plants du D30 seraient soumis à un stress hydrique et les autres non.

\section{Résultats des isolements mycologiques Analyse de parties de végétaux}

Les agents pathogènes isolés des parties pourries des cocotiers sont composés des champignons Botryodiplodia sp. et
Thielaviopsis sp. et des bactéries Erwinia sp. A part la noix, les bactéries interviennent sur toutes les parties pourries (coeur, pédoncule de l'inflorescence, rachis et base de la flèche) du cocotier dépérissant. En proportion, ces bactéries surpassent de deux fois chacun des deux champignons. Leur présence peut alors suggérer qu'elles sont en partie responsables de ces pourritures observées sur le cocotier en phase du dépérissement.

\section{Analyse du sol}

Les résultats des deux méthodes utilisées sont contenus dans le Tableau 6.

Fusarium sp est le champignon qui a pu bien pousser dans la méthode du soil plate. Il est même le plus dominant (2/3 de fréquence d'apparition) dans la méthode de dilutionsuspension utilisée. Il a sûrement couvert les Aspergillus qui sont certainement les moins compétitifs dans cette méthode.

Les deux méthodes n'ont pas permis de faire une différence entre le témoin et le sol issu de parcelle contaminée. Ces champignons telluriques ne peuvent donc pas être la cause du dépérissement.

\section{Présentation des résultats de l'analyse au microscope électronique}

Parmi les échantillons utilisés pour les analyses, seuls ceux issus de feuilles et d'inflorescences ont donné des résultats satisfaisants.

\section{Observations faites sur les coupes de feuilles}

Les Figures 8a, 8b, 8c, 8d, 8e et $8 \mathrm{f}$ présentent des cellules issues de feuilles jeunes et adultes de cocotiers sains ou dépérissants.

Les Figures $8 b$, $8 c$ et $8 d$ montrent des structures nouvelles qui ne sont pas dans le témoin. A l'opposé de la Figure 8a les organites cellulaires ont disparu.

Sur la Figure 8e, de nouvelles structures (b) viennent s'ajouter au tableau d'éléments déjà cités (parois, organites cellulaires, structures de type a, noyau). Elles sont présentes uniquement dans la paroi des cellules. Elles sont groupées et ont à peu près 
la même taille. Elles sont entourées d'une membrane et sont munies d'un point au centre de la structure.

\section{Observations faites sur les coupes d'inflorescences}

Les Figures 9a et 9b qui sont issues des inflorescences, présentent des cellules avec des organites cellulaires. La Figure 9b montre les mêmes structures de type b que nous avons signalées dans les cellules de la feuille de cocotier malade. Il pourrait alors s'agir des structures normales de la cellule puisqu' elles se retrouvent aussi au niveau des cocotiers sains prélevés dans une région où la maladie ne sévit pas (Adiopodoumé).

Sur la Figure $9 \mathrm{c}$ on ne voit ni noyau ni organites cellulaires. Les particules de formes et de tailles variables déjà décrites sur la feuille se voient en abondance. La particularité de cette Figure réside dans la présence de cellule campagne. La présence de celle-ci suggère qu'il s'agit d'une cellule criblée qui est ici photographiée.

Les Figures 9d et 9e montrent seulement des plages de ces particules de type a entourées de membrane tripartite avec un contenu dense assimilable aux ribosomes. Sur la figure $9 \mathrm{e}$, il y a un bourgeonnement de l'organisme au centre.

Les observations des coupes montées sur grilles ont montré avec les parties de feuilles et des inflorescences des particules de tailles et de formes variables. Ces particules, absentes dans les témoins, s'observent aussi bien dans les cellules libériennes ou non. La structure interne comporte des ribosomes (grossissement 28000, 45000) et au grossissement 45000 (Figures 9d et 9e) nous constatons qu'elles sont entourées d'une membrane tripartite. Les organismes dont les descriptions correspondent à ceux de notre étude sont les organismes de type mycoplasmes ou phytoplasmes. Cela signifie que hors des inflorescences, les phytoplasmes (mycoplasmes) peuvent se retrouver dans les feuilles au niveau des nervures, qui font partie du système conducteur ou phloème comme l'avait signalé Dollet en 1978.

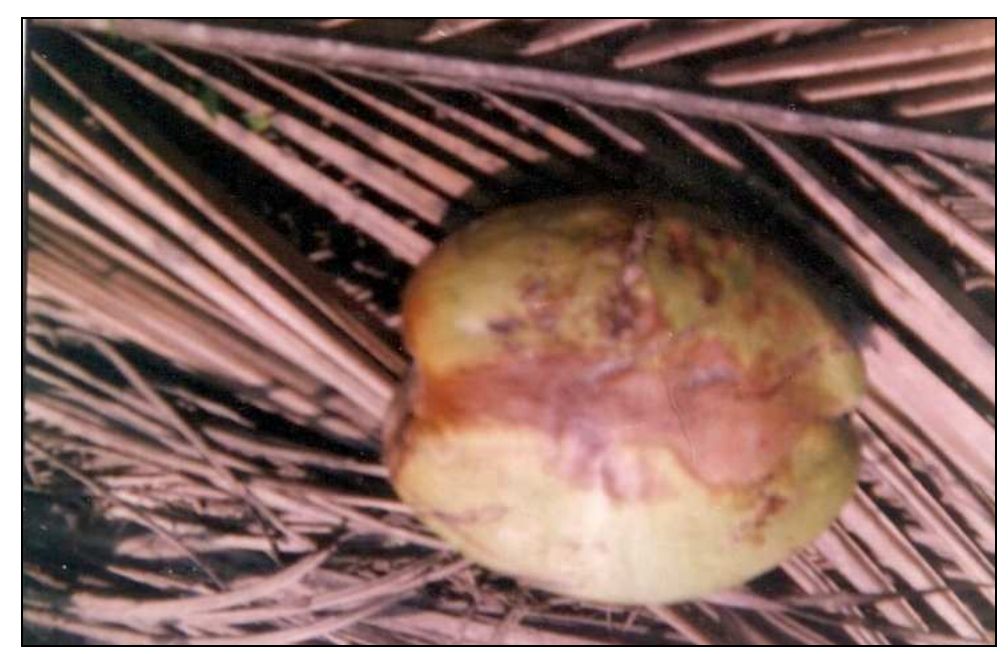

Figure 1: Symptôme de pourriture sur noix tombée de cocotier non dépérissant. 


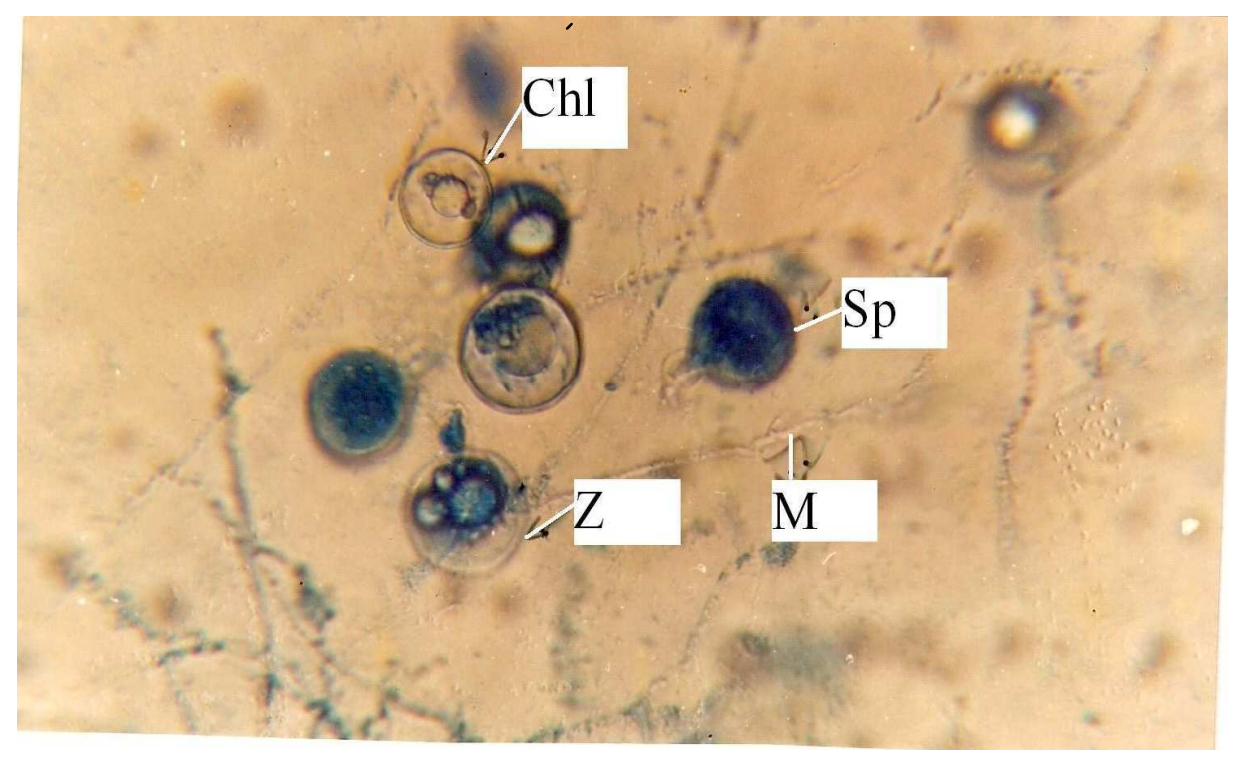

$\mathrm{Chl}=$ chlamydospore $; \mathrm{M}=$ mycélium $; \mathrm{Sp}=$ sporocyste $; \mathrm{Z}=$ zygote

Figure 2: Mycélium, organes de reproduction et de conservation.

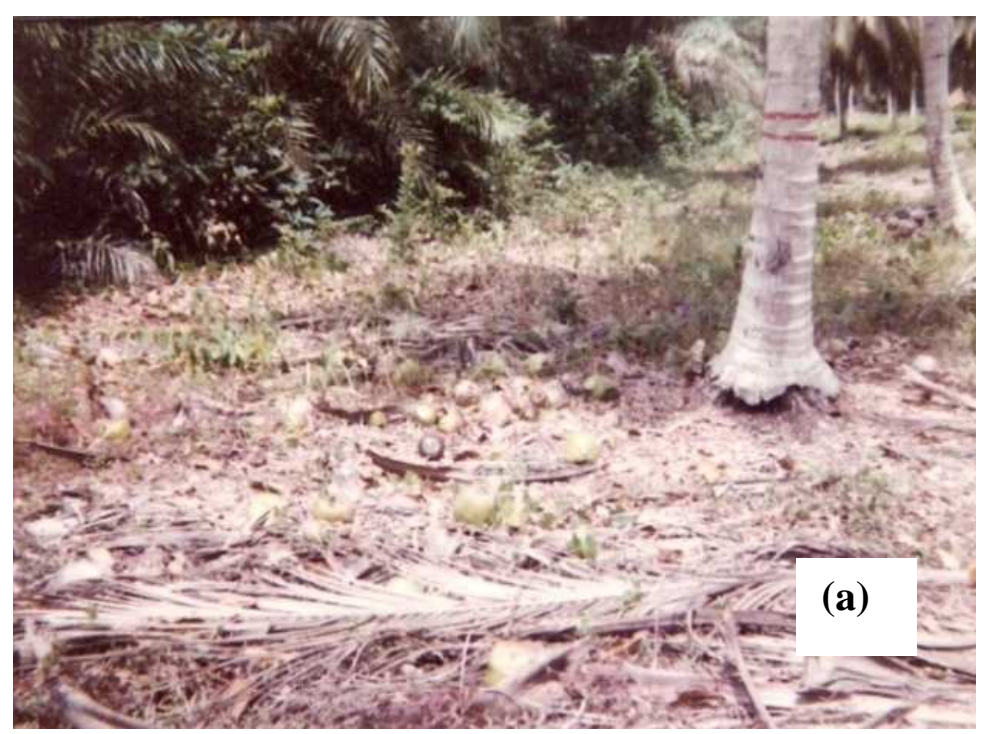



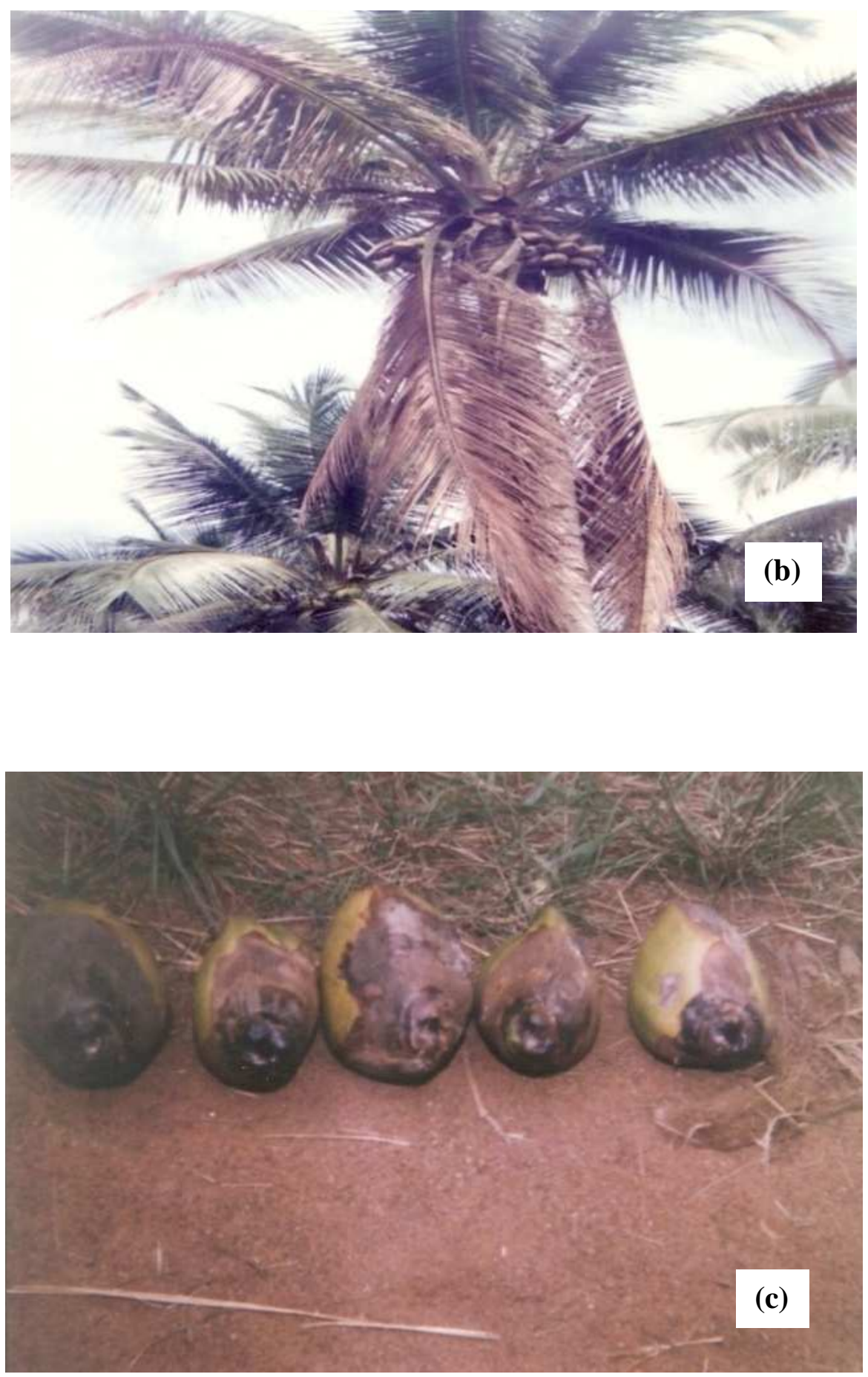


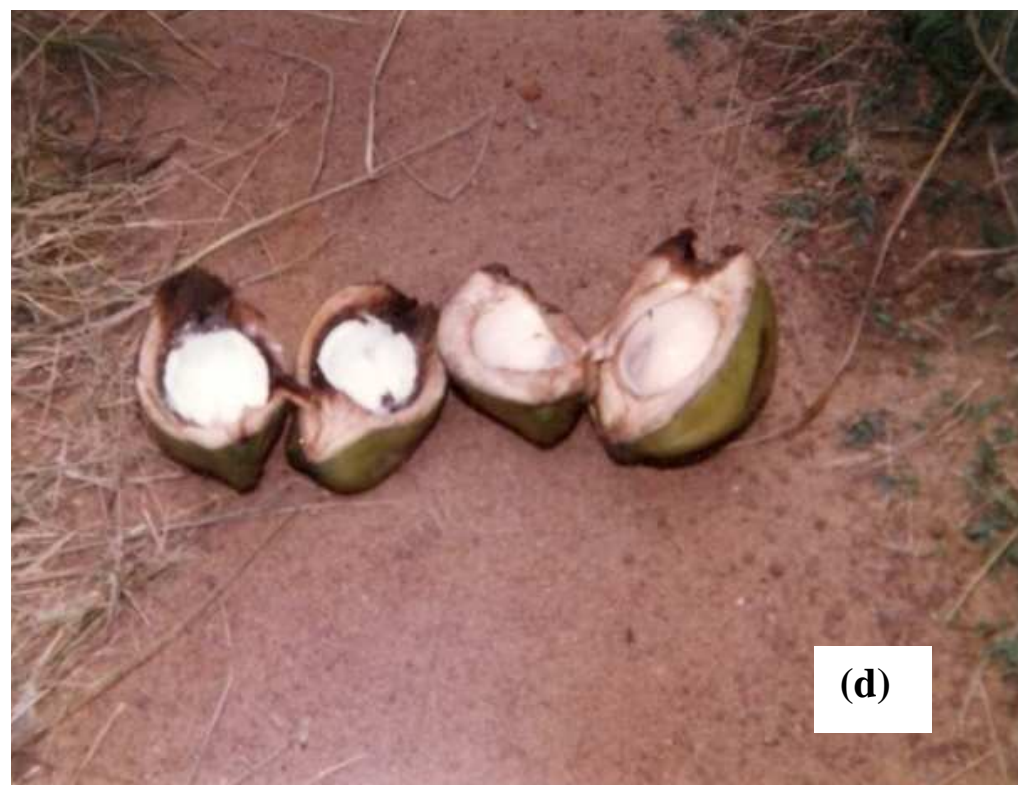

Figure 3: Symptômes du dépérissement mortel sur noix: (a) Chute de noix immatures, (b) Noix séchées sur le cocotier dépérissant, (c) Pourriture noirâtre de noix sur le proximal, (d) Coupe de noix tombées de côté cocotiers déperissants.

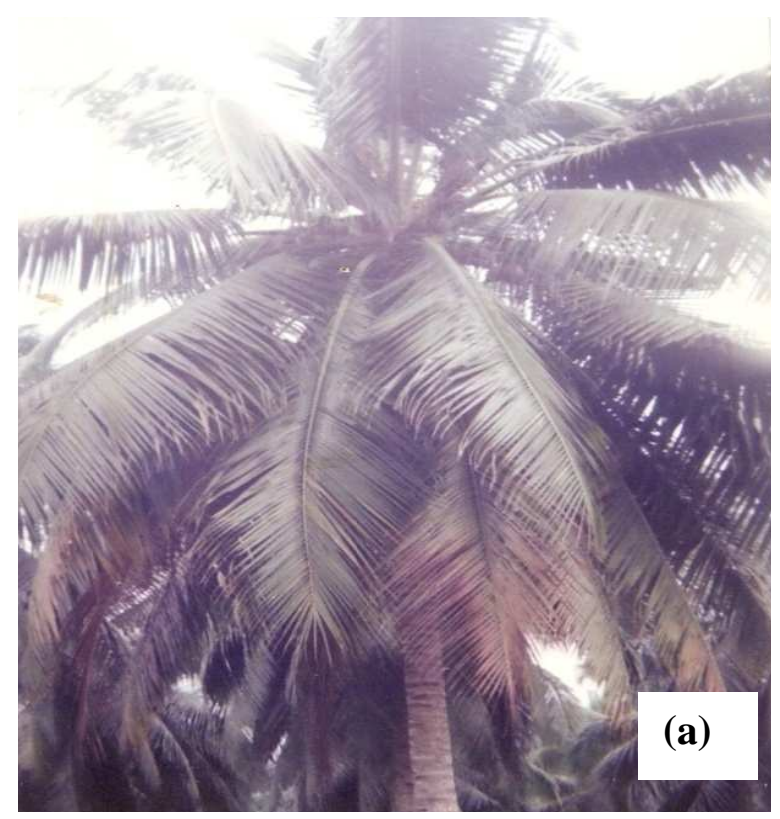



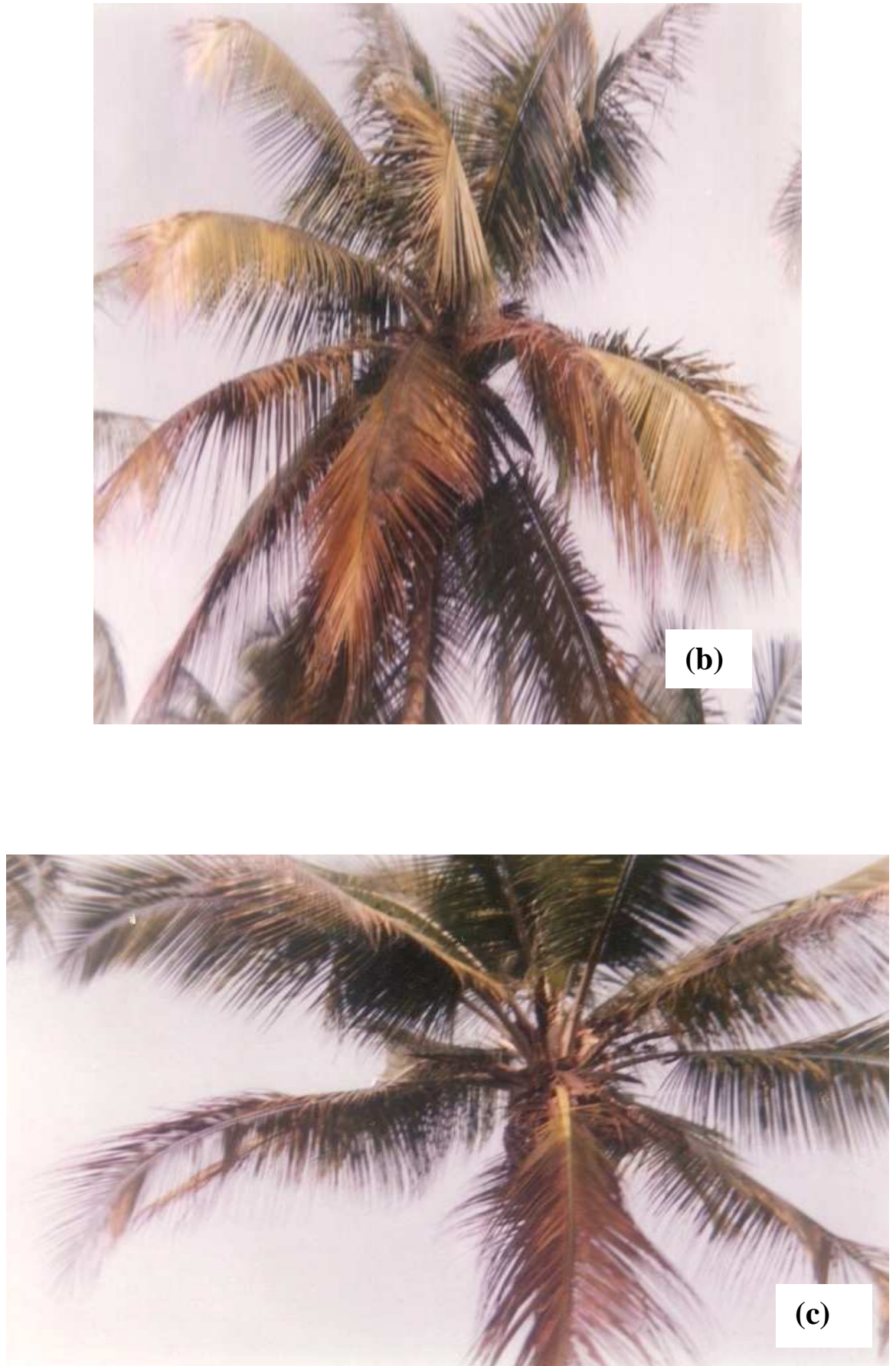

Figure 4: Symptômes de jaunissement sur cocotiers dépérissants. (b) Evolution du jaunissement sur le cocotier, (c) Cocotier trois mois après le début du jaunissement, (a) Début de jaunissement sur les feuilles basses. 

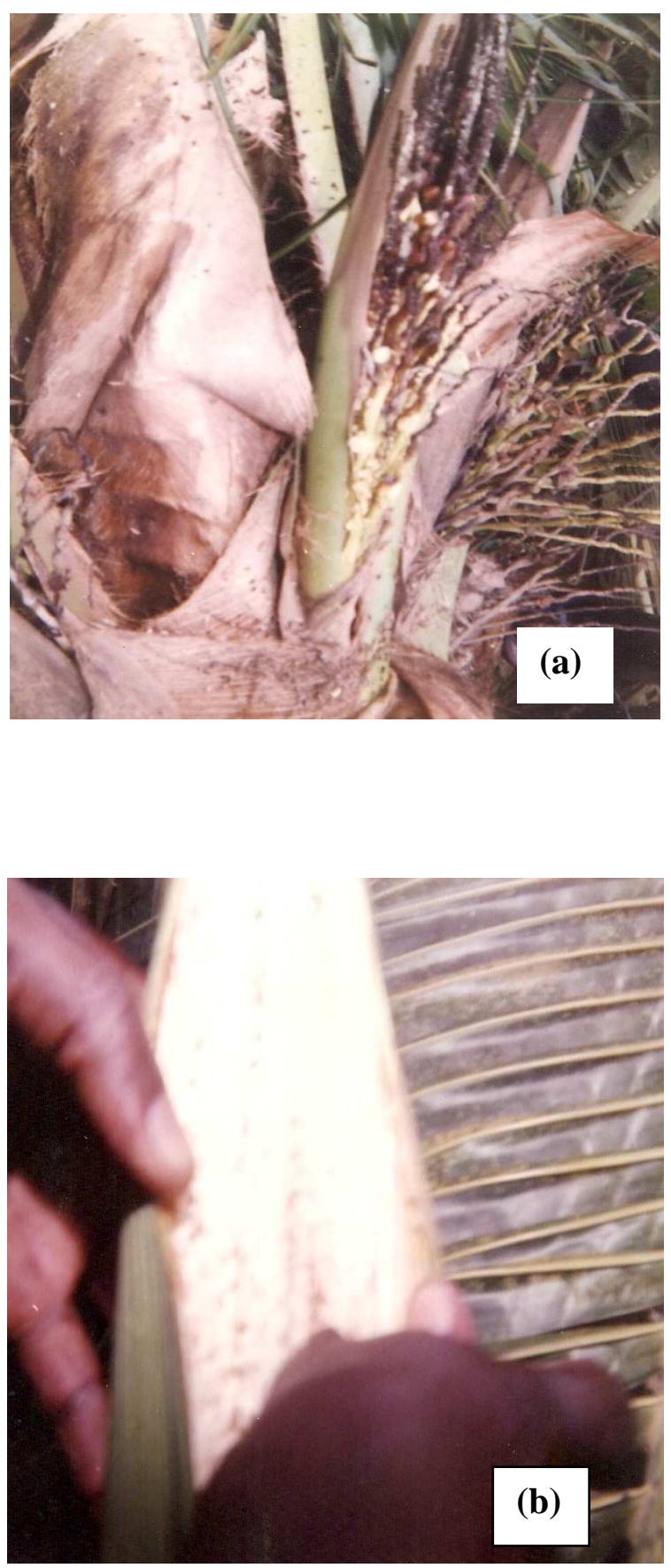

Figure 5 : Symptômes du dépérissement sur les inflorescences. (a) : Avortement des fleurs mâles et femelles et noircissement des épillets, (b) : Noircissement des fleurs dans une inflorescence non ouverte. 


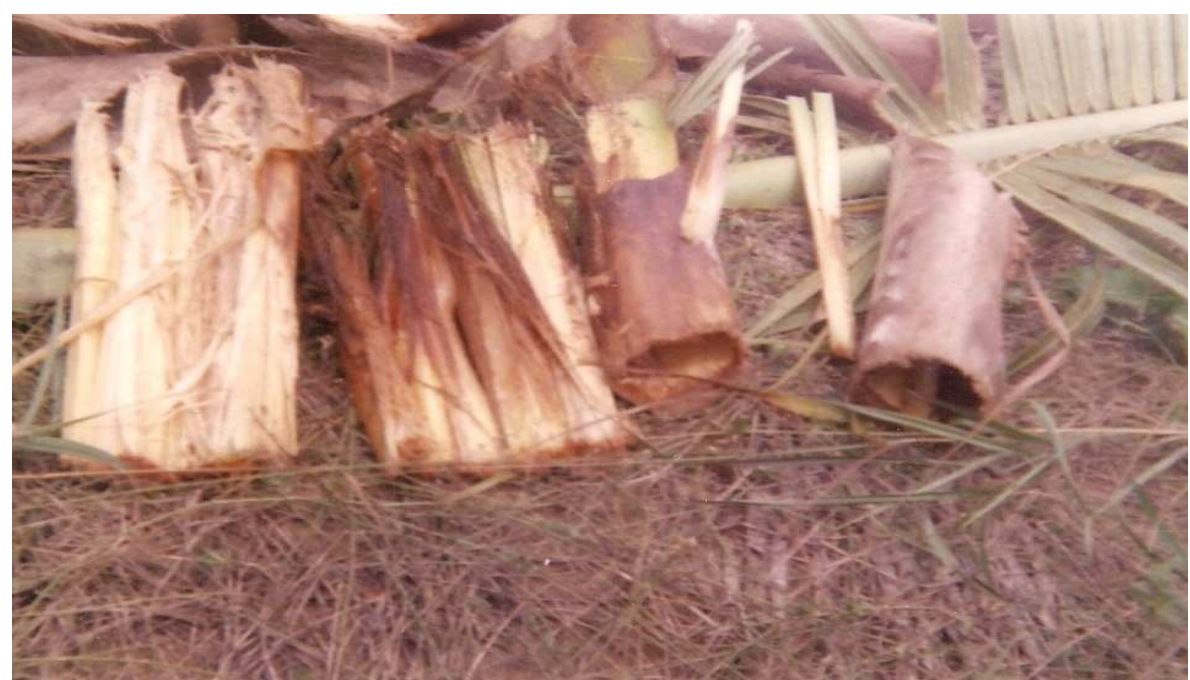

Figure 6 : Pourriture de la flèche et des feuilles internes.

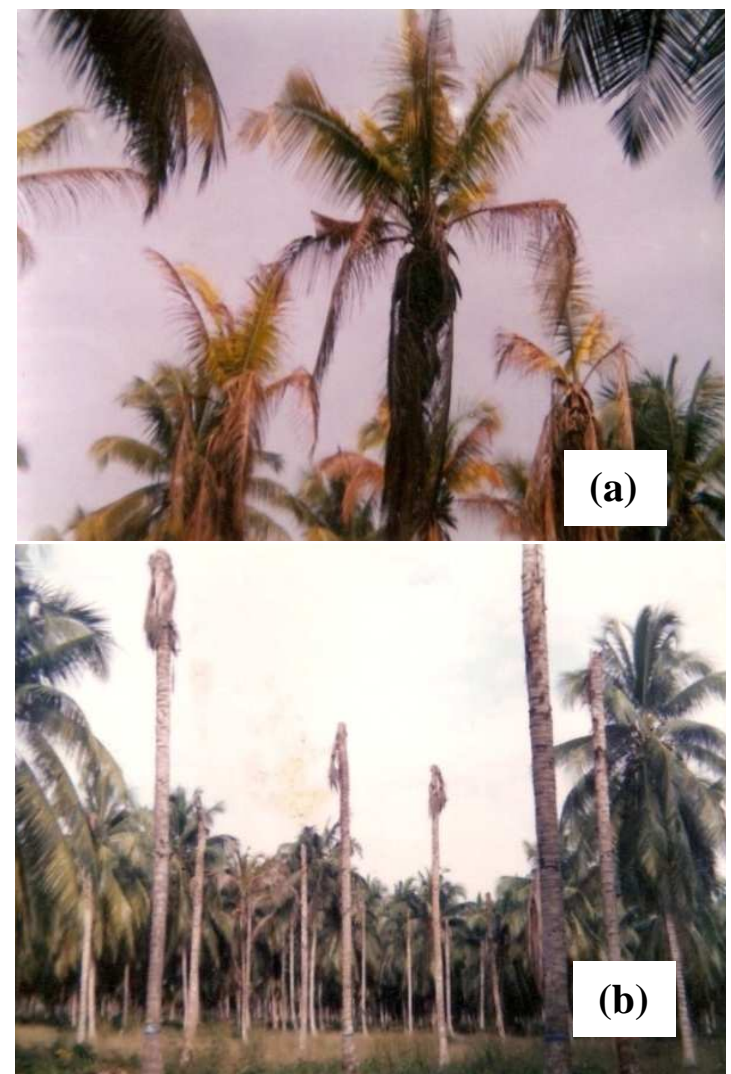

Figure 7: Cocotiers au stade final du dépérissement mortel. (a): Flétrissement de la couronne foliaire, (b): Cocotiers ayant perdu leur couronne 7 à 8 mois après le début du dépérissement. 

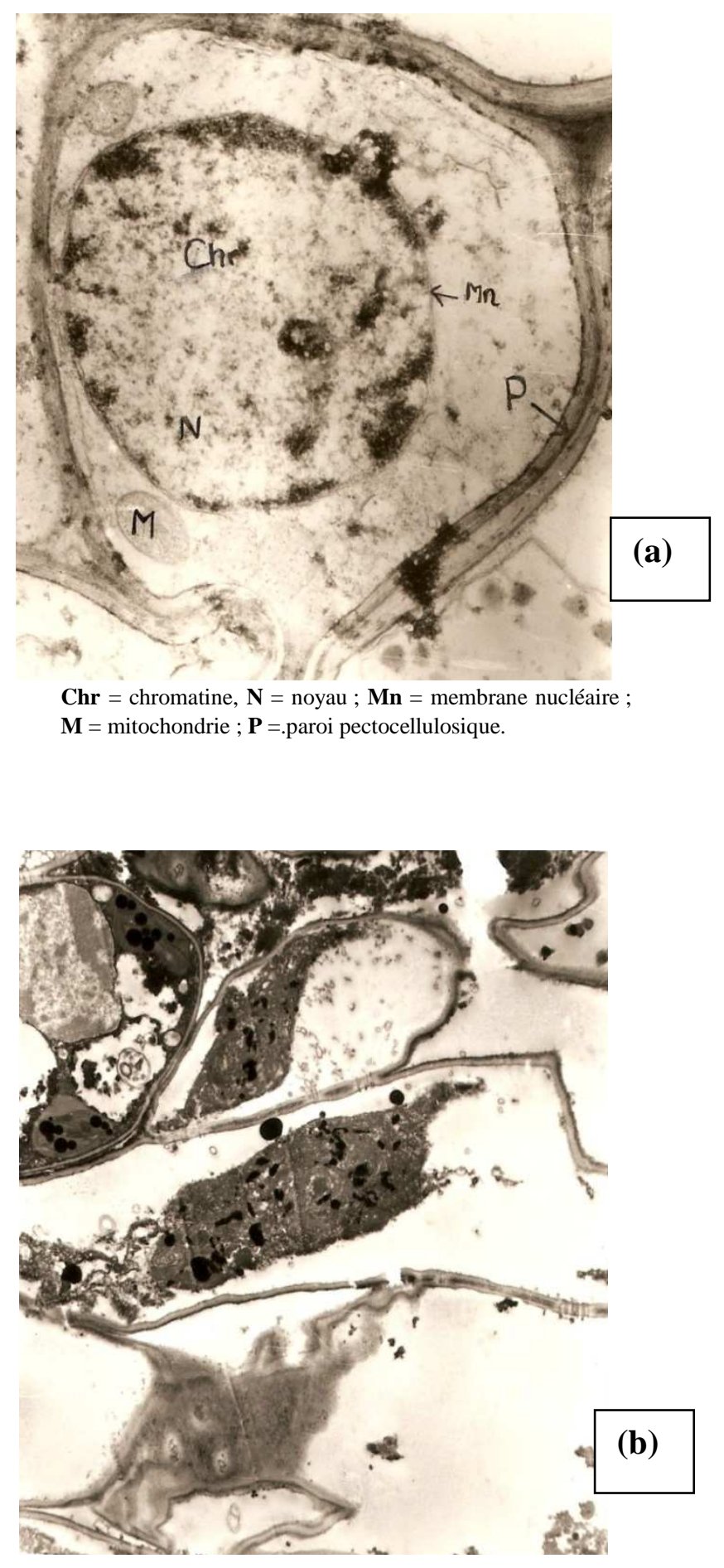

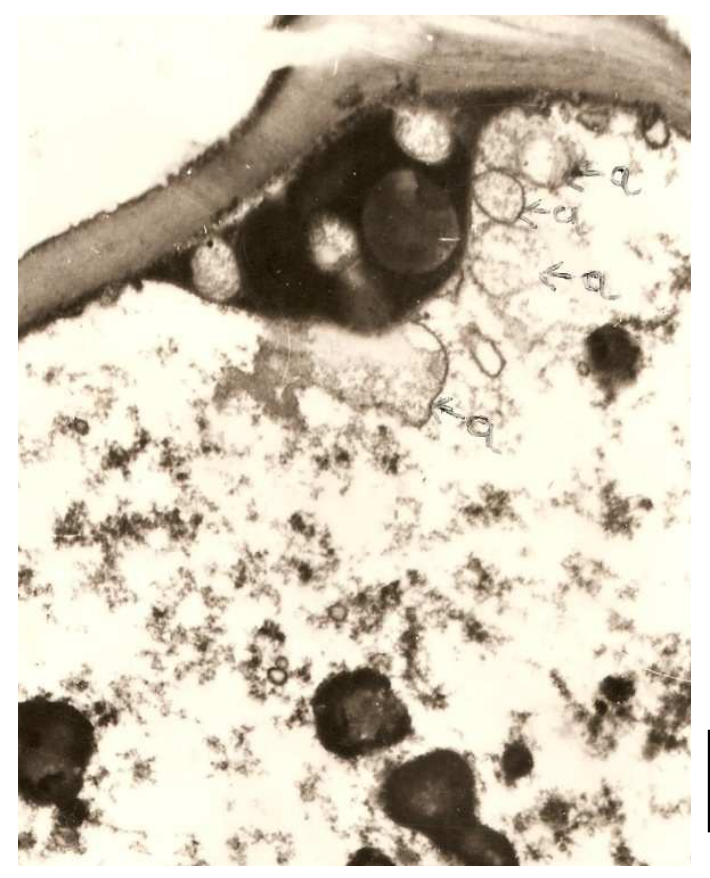

(c)

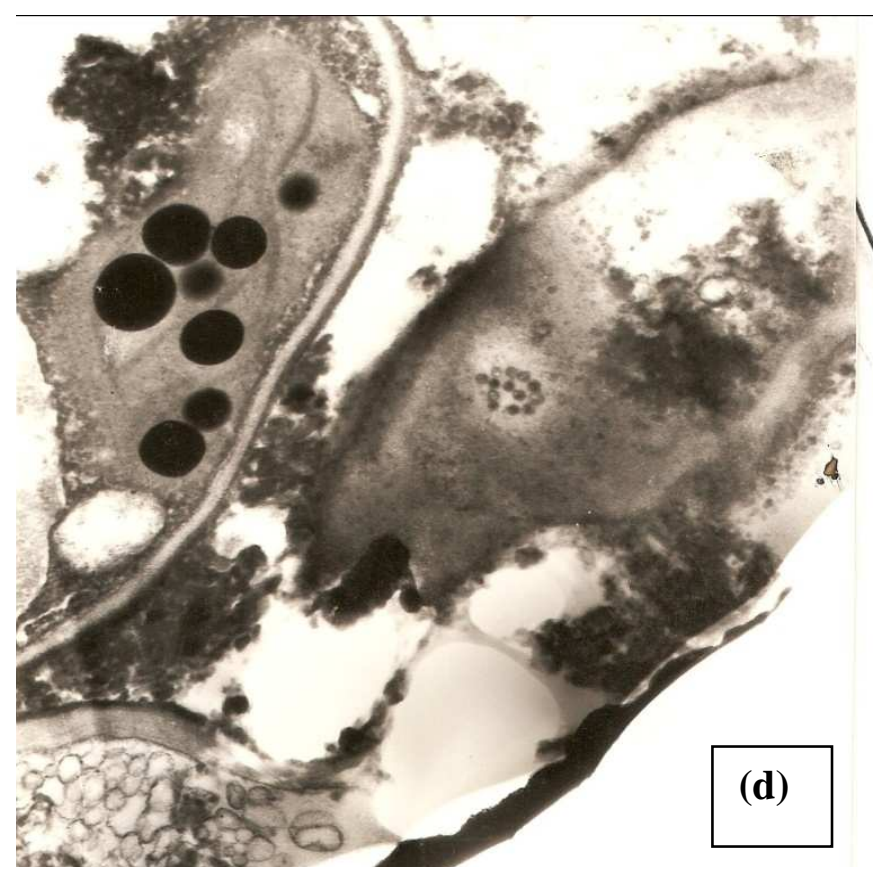



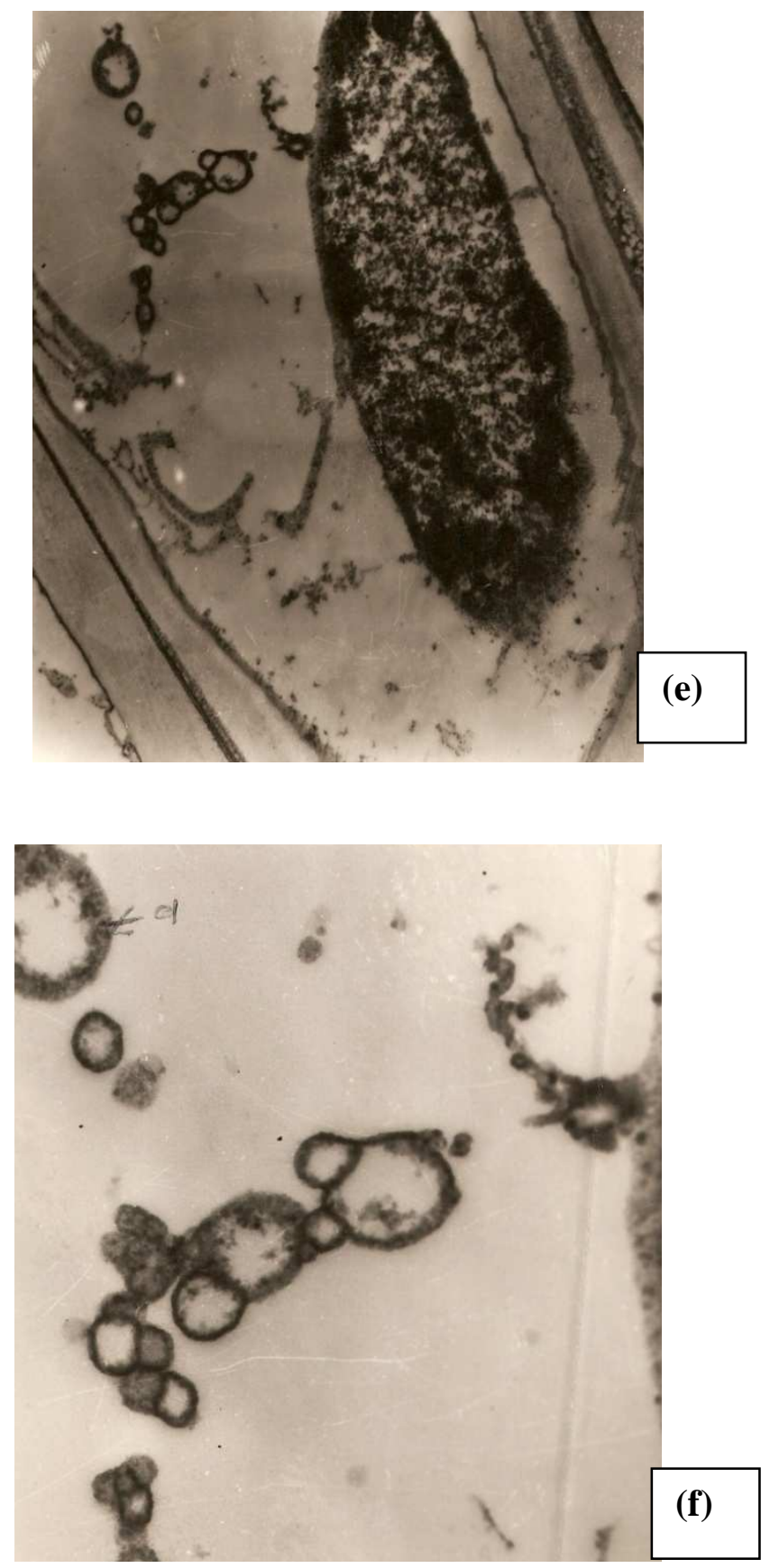

Figure 8 : Cellules issues de feuilles jeunes et adultes de cocotiers dépérissants ou sains. (a) : x 18000 Cellules de feuilles de cocotier sain (témoin), (b) : x 3000 Cellules de cocotiers dépérissants montrant une dislocation du hyaloplasme et des particules de type a, (c) : x 12000 Cellule de cocotier dépérissant avec une grosse vacuole et une plage de particules de type $\mathrm{a},(\mathbf{d}): \mathrm{x} 15000$ Cellule de cocotier dépérissant montrant un chloroplaste et des particules de type a et b, (e): x 10500 Cellule de jeune feuille de cocotier dépérissant présentant un noyau et une plage de particules de type a. le contenu est plus ou moins dense, (f) : x 28000 Particules de type a issues de la figure 8e. Ces particules ont des formes arrondies et variées. 

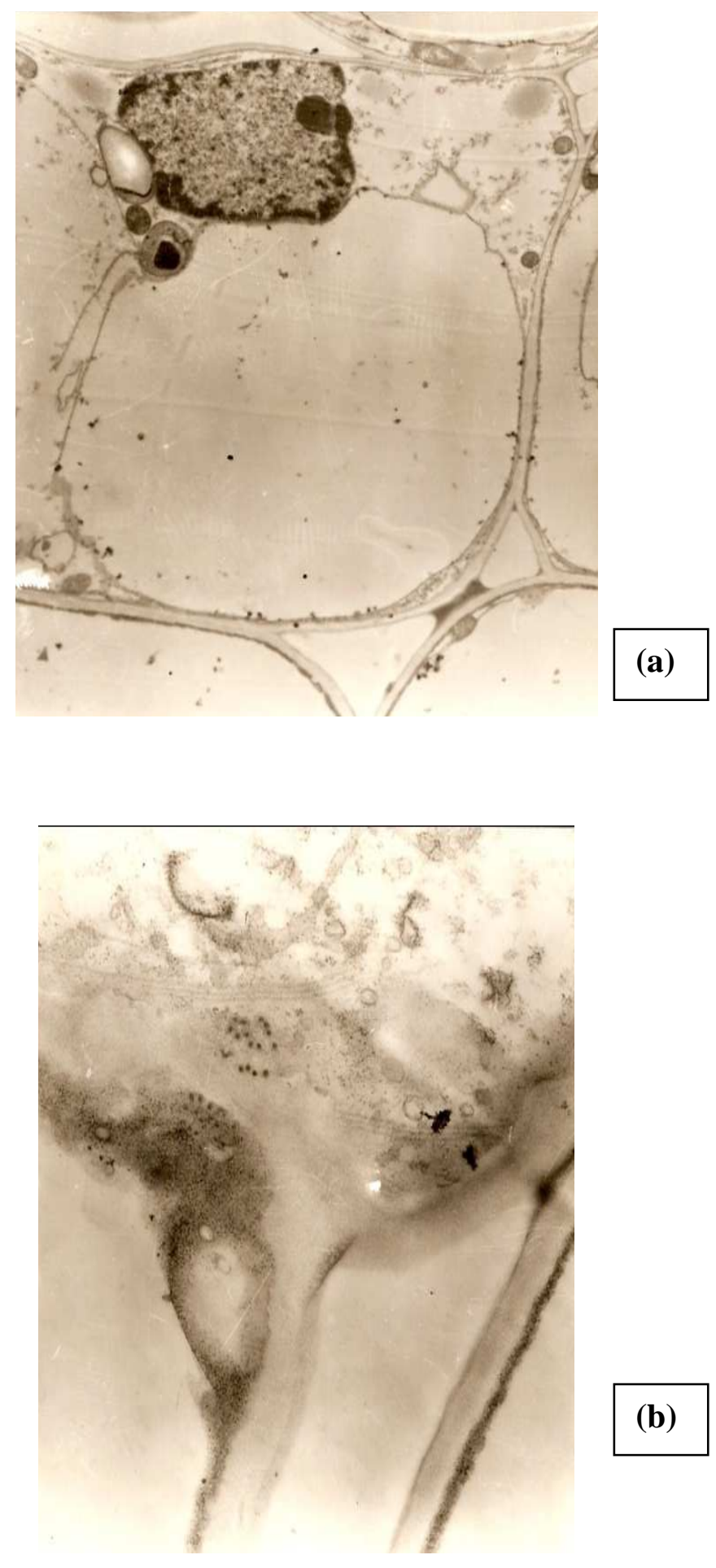

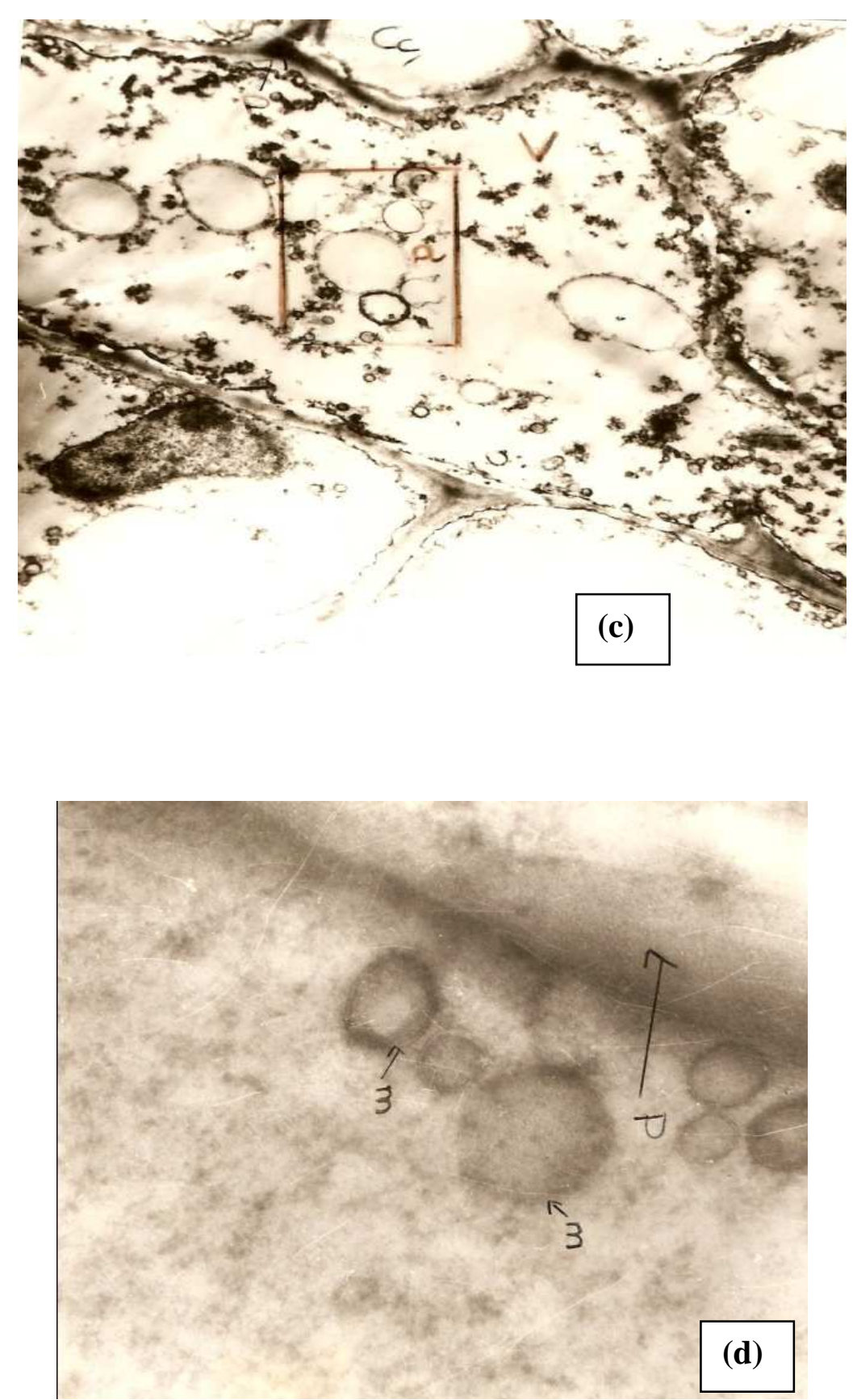

$\mathrm{m}=$ membrane tripartite, $\mathrm{P}=$ paroi pectocellulosique 


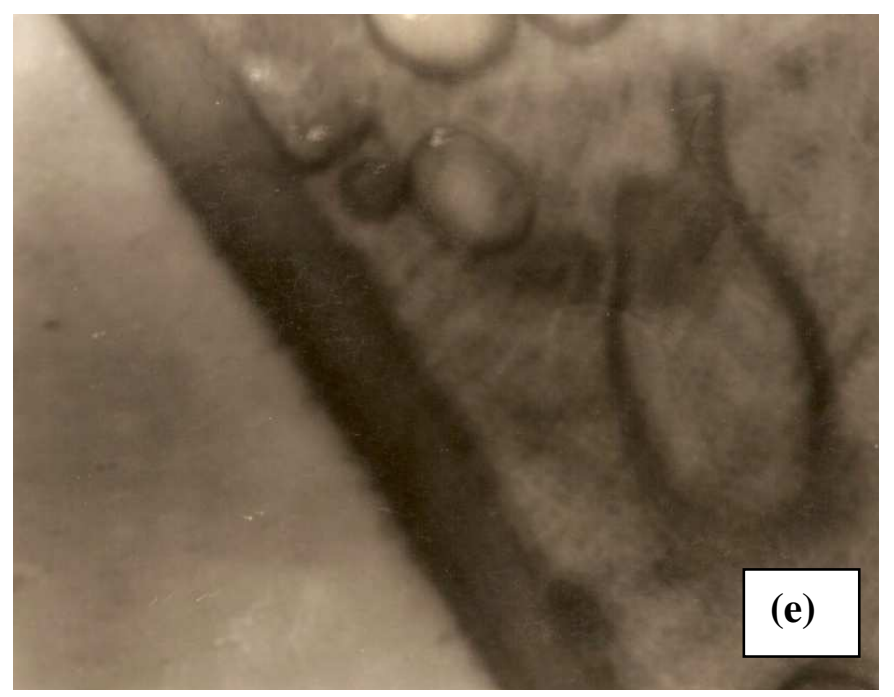

Figure 9: Coupes d'inflorescences de cocotiers dépérissants et sains. (a) : x 4500 Cellules de cocotier témoin montrant des particules de type b, (b) : x 18000 Cellules de cocotier témoin. Dans la paroi, (c) : x 4500 Plages de particules de type a et une cellule campagne, (d) : x 45000. Plage de particules de type a entourées de membrane tripartite, (e) : x 45000. Bourgeonnement de la cellule.

Tableau 1: Liste de mauvaises herbes collectées.

\begin{tabular}{ll}
\hline Familles & Espèces \\
\hline Amaranthacées & Paplia lappcea \\
Apocynacées & Funtumia africana \\
& Rauvlfia vomitoria \\
& Baissea laxiflora \\
Ascipiadacées & Pergularia daemice \\
Asteracées & Chromoleana odorata \\
Cypéracées & Mariscus umbellatus \\
Flagellariacées & Flagelliaria guineensis \\
Graminées & Digitaria velutna \\
& Rhynchaelitrum roseum \\
Hypericacées & Harungana madagascariensis \\
Melastomacacées & Dissocies rotundifolia \\
Rubiacées & Cephelis peduncularis \\
& Oldenlandia corymbosa \\
& O. affinis \\
Moracées & Mussaeenda chipii \\
Rosacées & Ficus exasperata \\
Olacacées & Chrysobalanus elliptocus \\
Menispermacées & Heistereria parvifolia \\
Verbenacées & Epinetrum cordifolium \\
& Clerodentum scandens \\
Papilionacées & C. umbellatum \\
\hline
\end{tabular}


Tableau 2: Plants morts par année de culture et par variété.

\begin{tabular}{lcc}
\hline Années de culture & \multicolumn{2}{c}{ mortalité } \\
\cline { 2 - 3 } & GOA & Hybride \\
\hline 1969 & 83 & \\
1970 & 182 & \\
1971 & 113 & \\
1973 & & 118 \\
1974 & & 1555 \\
1975 & & 242 \\
1976 & & 374 \\
\hline
\end{tabular}

Tableau 3: Mortalité au B21 et au B22 en fonction de la mortalité totale des cultures de 1974.

\begin{tabular}{lc}
\hline Superficie totale en ha & $\mathbf{1 2 8 0}$ \\
\hline Superficie B21 et B22 en ha & 52 \\
Nombre de plants morts pour les cultures de 1974 & 1555 \\
Nombre de plants morts au B21 et au B22 & 459 \\
Pourcentage par rapport à la superficie totale & 4,06 \\
Pourcentage de mortalité par rapport à la mortalité totale & 35,86 \\
\hline
\end{tabular}

Tableau 4: Résultats de la visite au champ et symptômes observés selon les parcelles.

\begin{tabular}{lccc}
\hline Numéro de parcelle & $\begin{array}{c}\text { Année de } \\
\text { culture }\end{array}$ & $\begin{array}{c}\text { Superficie } \\
\text { en ha }\end{array}$ & Observations \\
\hline B15 & 1974 & 25,5 & cas de foudre \\
F25 & 1974 & 19 & foudre ou mortalité sans de nouveaux cas \\
A11 & 1970 & 28,5 & dépérissement et mortalité \\
A1 & 1969 & 13,80 & dépérissement et mortalité \\
F27 & 1975 & 18 & cas de foudre \\
B14 & 1974 & 26 & mortalité mais pas de dépérissement \\
B18 & 1974 & 26 & foyer de dépérissement et mortalité \\
D5 & 1970 & 22 & chute de noix immatures due à $P$. katsurae \\
\hline
\end{tabular}


Tableau 5: Nombre de plants morts (M) et dépérissants (D) par période de comptage.

\begin{tabular}{|c|c|c|c|c|c|c|c|c|c|c|}
\hline \multirow[t]{3}{*}{$\begin{array}{l}\text { Période de } \\
\text { comptage }\end{array}$} & \multicolumn{4}{|c|}{$\begin{array}{l}\text { Nombre de cas comptabi- } \\
\text { lisés }\end{array}$} & \multicolumn{2}{|c|}{$\begin{array}{l}\text { Impact du } \\
\text { dépérissement }\end{array}$} & \multicolumn{2}{|c|}{$\begin{array}{c}\text { Evolution par } \\
\text { période de } \\
\text { comptage }\end{array}$} & \multicolumn{2}{|c|}{$\begin{array}{l}\text { Pourcentage } \\
\text { d'infection }\end{array}$} \\
\hline & & & B22 & & & & & & & \\
\hline & $\mathrm{M}$ & $\mathrm{D}$ & M & D & B21 & B22 & $\begin{array}{c}\mathrm{B} 2 \\
1\end{array}$ & B22 & B21 & B22 \\
\hline Janvier & 166 & 31 & 293 & 46 & 4,98 & 8,22 & & & 0,84 & 1,13 \\
\hline Mars & 170 & 24 & 310 & 60 & 5,36 & 8,97 & 10 & 14 & 1,1 & 1,57 \\
\hline Juin & 201 & 67 & 356 & 98 & 6,78 & 11 & 25 & 38 & 1,79 & 2,6 \\
\hline Août & 251 & 102 & 402 & 140 & 8,93 & 13,14 & 35 & 42 & 2,97 & 3,76 \\
\hline
\end{tabular}

Tableau 6 : Identification des champignons par les méthodes de dilution-suspension et soil plate.

\begin{tabular}{lcc}
\hline Types de sol & \multicolumn{2}{c}{ Méthode utilisée } \\
\cline { 2 - 3 } & $\begin{array}{c}\text { Dilution -suspension et } \\
\text { fréquence }\end{array}$ & Soil plate \\
\hline Sol noir & Fusarium $(2 / 3)$ & Fusarium \\
& Geotrychum & Geotrychum \\
Sol rougeâtre & Fusgillus $(1 / 3)$ & \\
& Fusarium $(2 / 3)$ & Fusarium \\
Témoin sol noirâtre & Aspergillus $(1 / 3)$ & Geotrychum \\
& Fusarium $(2 / 3)$ & Fusarium \\
Témoin sol rougeâtre & Geotrychum & Geotrychum \\
& Aspergillus $(1 / 3)$ & \\
& Fusarium $(2 / 3)$ & Fusarium \\
& Aspergillus $(1 / 3)$ & Geotrychu \\
\hline
\end{tabular}

\section{DISCUSSION}

La pluviométrie et le bilan hydrique enregistrés à Grand-Lahou se trouvent dans les normes exigées pour la culture du cocotier (CNRA, 2006). Il en est de même pour le sol qui n'est pas tout à fait gravillonnaire (Yao, 1997). Aussi, les arbres marqués en début de dépérissement ont atteint le stade final de la maladie. Aux vues de tous ces faits, nous pouvons dire que ce fléau ne se trouverait pas sûrement justifié par le stress hydrique.

Dans le cas précis de nos observations, si certaines noix présentent des symptômes de pourritures dues au $P$. katsurae, celui-ci n'est pas le problème pathologique préoccupant du moment dans la cocoteraie de Grand-Lahou. Cela s'explique par le fait que non seulement l'intensité n'est pas forte mais aussi, dans le cas d'une recrudescence de cette maladie, la lutte chimique (Pohé et al., 2003 ; Allou et al., 2001) et génétique (Allou et al., 2002) sera mieux indiquée pour venir à bout de celle-ci. Le problème pathologique majeur qui préoccupe tout travailleur de SICOR ailleurs comme à Grand-Lahou, est le dépérissement mortel des cocotiers par sa gravité puisqu'un arbre atteint est destiné à mourir, donc exclu de l'effectif du peuplement en cocotiers de la plantation. Il va s'en dire que la superficie en rapport va en diminuant, puisque le 
dépérissement progresse lentement mais sûrement.

Les champignons isolés au niveau du sol ne peuvent pas être à l'origine de ce dépérissement car, la dissection et le déracinement de cocotiers malades ont montré que la pourriture ne provient pas de la base. Aussi aucune bibliographie ne mentionne de maladie sur le cocotier due au Fusarium.

Les isolements faits sur les parties de plants attaqués ont révélé deux agents mycologiques: Botryodiplodia sp. et Thielaviopsis sp. Ces agents pathogènes bien que signalés comme agents de Stem bleeding et de Leaf blight (Warwick et al., 1991; Warwich et Passos, 2009 ) ont été isolés dans les pourritures avancées et non dans le front de croissance. Il en est de même pour Erwinia. Par ailleurs, tous ces trois agents pathogènes ont été signalés comme faisant partie du cortège de saprophytes sur les organes déjà détruits par un autre parasite primaire (Pohé, 1996). Probablement, ceux-ci s'installent à la suite d'un affaiblissement des tissus du cocotier par un autre agent que nos techniques de mise en évidence des champignons n'ont pas permis d'identifier.

Ce dépérissement trouverait son origine dans l'existence d'organisme de type mycoplasmes (Dollet et al., 2009, 2011) comme le montrent nos résultats d'analyse au microscope électronique. Ces observations s'apparentent aux résultats obtenus par Dollet et Giannotti (1976) et Dollet et al. (1977) qui ont étudié respectivement le dépérissement mortel du cocotier au Togo et au Cameroun. Les symptômes que nous avons observés vont également dans le même sens que ceux décrits par Eziashi et Omamor (2010). Tous ces constats concourent pour dire que le dépérissement mortel qui a fait l'objet de notre étude s'assimile au jaunissement mortel du cocotier comme il a été dénommé par ces mêmes auteurs. La détection de ces phytoplasmes est une première étape qui doit être coordonnée avec l'étiologie et avec leur transmission. Nous recommandons que la microscopie électronique soit suivie par la sérologie et l'amplification moléculaire en chaine ou polymerase chain reaction (PCR) (Cousin et Boudon-Padieu, 2001; Myrie et al., 2006 ; Brown et al., 2008 ; Nejat et al., 2009) des échantillons de plants sains et malades et d'extraits d'insectes. De même, un traitement des cocotiers en début de dépérissement (début de chute des noix) avec un antibiotique du groupe des tétracyclines en injection dans le tronc s'avère nécessaire. Ces organismes sont sensibles à cet antibiotique. Ainsi, l'approfondissement de ces résultats d'analyse et la rémission de plants traités viendront à point pour consolider de telles études. Retenons par ailleurs qu'une distance d'environ $300 \mathrm{~km}$ sépare ce nouveau foyer de celui du Ghana qui se trouvait à $70 \mathrm{~km}$ de la frontière ivoirienne. Comment explique t-on alors l'existence de cette maladie à GrandLahou et non à Assinie qui se trouve proche de la frontière ivoiro-ghanéenne? Probablement, ce saut se justifie dans le mode de dissémination de cette maladie qui est parfois imprévisible. Mariau et al. (1996) et Bonnot et al. (2010) ont montré que celle-ci peut faire des bonds de 10,70 , et même 450 $\mathrm{km}$. Certainement, le microclimat de l'île où se trouve la plantation de la SICOR s'y prête mieux à son épanouissement qu' Assinie ou ailleurs.

Les particules de type $b$ que nous avons observées doivent aussi faire l'objet d'une étude approfondie pour bien appréhender les membranes.

La tétracycline désignée a déjà été utilisée en Floride pour lutter contre cette maladie sur les cocotiers touristiques (McCoy, 1974, 1982). Ce même auteur a démontré en 1978 que la dose de 3 g/arbre utilisée pour la lutte contre le jaunissement mortel n'est pas toxique pour le consommateur de noix comme c'est le cas de la SICOR qui fabrique des produits alimentaires. Mais, en étendant la discussion au niveau des paysans, il est utopique de préconiser cette méthode de lutte car, la bourse de ceux-ci ne leur permet pas de 
l'utiliser à cause du prix des antibiotiques qui est en général très élevé. Seule l'utilisation de variétés résistantes ou même tolérantes serait un salut. Cette voie est encore difficile à aborder, car non seulement, la maladie ne se manifeste pas sur les jeunes cocotiers mais aussi, la période d'incubation sur les arbres susceptibles (arbres en production) est de deux ans (Dery et al., 1996; Mariau et al., 1996). Aussi, les essais de reproduction de la maladie sont laborieux. Les variétés reconnues comme tolérantes dans un pays après la mise en place d'un champ de comportement ne le sont pas forcement dans un autre. Et, comme la maladie ne se manifeste pas sur le jeune cocotier, une autre voie de recherche peut être dirigée dans ce sens. Il s'agit de l'étude comparative de la physiologie du cocotier jeune et adulte. Si cette version est vérifiée, il existerait alors dans l'organisme de celui-ci un mécanisme de résistance qui empêcherait la maladie de s'y manifester.

Pour ce qui concerne la lutte, nous préconisons l'abattage systématique des cocotiers suspectés comme dépérissants pour éviter la contamination de nouveaux plants. En effet, plusieurs insectes de l'ordre des Homoptères sont reconnus comme vecteurs de cette maladie dans les pays où elle sévit (Myrie et al., 2008 ; Philippe et al., 2008). Il s'agit notamment de: famille des Cixiidae: Myndus crudus van duzee Van Duzee, M. adiopodoumeensis; famille des Derbidae: Diostrombus sp. Kamendala sp., Lydda sp., Phenice sp., Malenia sp. et Cedusa sp. Nous recommandons la poursuite des piégeages pour identifier l'insecte vecteur (Pilet et al., 2008). Cette étude permettra d'identifier l'insecte vecteur dans le cas de la Côte d'Ivoire, d'appréhender les variations saisonnières de sa population afin de déterminer ces périodes de pullulation. L'inventaire des mauvaises herbes a révélé que les espèces comme Chromoleana odorata, Mariscus sp sont des lieux de ponte de la femelle du vecteur (Dery et al., 1996).
L'étude du vecteur intégrera le suivi des mauvaises herbes pour connaître les lieux de ponte de la femelle et éventuellement le cycle de reproduction. En effet, la connaissance de l'agent vecteur et son lieu de reproduction aideront dans les travaux à venir. Il faudra faire des élevages et des essais de reproduction de la maladie sous cage par des transmissions afin de s'assurer de son rôle de vecteur.

\section{Conclusion}

Au terme de notre étude, nous retenons que le dépérissement observé dans la cocoteraie de Grand-Lahou est causé par la présence de microorganismes de type phytoplasme dans les cellules des plantes atteintes. Et, en considérant le syndrome de cette maladie, nous pouvons dire qu'elle s'apparente aux maladies à jaunisse du cocotier déjà identifiées au Togo, au Ghana et au Cameroun.

Par ailleurs, une vérification de ces résultats est indispensable, en faisant un traitement des arbres atteints par un antibiotique du groupe des tétracyclines qui a un effet toxique sur l'agent pathogène.

Cette maladie fait d'énormes ravages dans les pays hôtes. Au Togo et au Ghana, elle a détruit des milliers d'hectares de cocoteraie allant même à annuler leurs exportations de coprah. Il devient donc impératif de s'interroger sur le sort des paysans de GrandLahou dont la seule activité rentable est l'exploitation des noix de coco sous forme de coprah. Le cocotier présente un très grand nombre d'avantages dans le milieu paysan à savoir:

- l'adaptation au milieu villageois (fabrication de coprah avec les moyens artisanaux très simples et à moindres coûts) ;

- la possibilité d'associations culturales (l'association cocotier-manioc et bananier plantain est la plus rencontrée (Enin et al., 2008), n'empêche que d'autres associations soient possibles: cocotier-caféier, cocotiercacaoyer lorsque l'éclairage au sol devient 
important) (Taffin et Sangaré, 1989). C'est pourquoi la Côte d'Ivoire doit prendre rapidement et de manière efficace des mesures pour limiter la progression de cette maladie et mettre à l'abri les exploitants en cocoteraie.

Sur une longue période, au plan national, les chercheurs devraient mettre en place un champ de comportement dans la région de Grand-Lahou sachant que les essais de transmission sont laborieux. Cette disposition permettra de sélectionner d'ores et déjà les écotypes qui se montrent tolérants. Les premiers résultats qui en découleront pourront faire l'objet d'un vaste programme de sélection. Les prédispositions pourront circonscrire cette maladie dans la région de Grand-Lahou sur l'île où se trouve la cocoteraie de la SICOR. Cette mesure sera facilitée par l'existence déjà en Côte d'Ivoire d'un champ de conservation des écotypes sur la station de recherche de l'ex IDEFOR/DPO (Institut des Forêts/ Département des plantes oléagineuses).

\section{REFERENCES}

Allou K, Bourdeix R, Aké S, Konan J-L, Zakra N. 2002. Phytophthora katsurae (Pythiaceae) du cocotier en Côte d'Ivoire. Toléreances variétales de 53 hybrides et données épidémiologiques de base. Agronomie Africaine, 14(2): 99-115.

Allou K, De Franqueville H. 2001. Efficacité comparée du Phosétyl-Al et de l'acide phosphoreux dans la lutte contre Phytophthora katsurae du cocotier. Agronomie Africaine, 13(3): 131-139.

Anonyme. 1997. Compte rendu de passation de service entre MM OGRA Robert, CCEA sortant et TAPE Zoré Emile, CCEA entrant. SICOR. 120p.

Anonyme. 1995. Rapport mensuel d'activité. Palmindustrie, $16 \mathrm{p}$.

Anonyme. 1989. Rapport d'activité IRHO, numéro spécial. Oléagineux, 44(4): 217.

Assa RR, Konan JL, Nemlin J, Prades A, Agbo N'zi G, Sié RS. 2006. Diagnostic de la cocoteraie paysanne du littoral ivorien. Sciences et Nature, 3(2): 113120.

Bachy A, Hoestra H. 1958. Contribution à l'étude de la maladie de Kaïncopé du cocotier au Togo. Oléagineux, 13: 721729.

Bonnot F, de Franqueville H, Lourenço E. 2010. Spatial and spatiotemporal pattern analysis of coconut lethal yellowing in Mozambique. Phytopathology, 100: 300312.

Brown SE, Been BO, McLaughlinWA. 2008. First report of lethal yellowing group (16 SrIV) of Phytoplasmas in Vernonia cinera in Jamaica. Plant Disease, 92(7): 1132.

CNRA. 2006. Bien cultiver le cocotier en Côte d'Ivoire. CNRA, 4 p.

Cousin M-T, Boudon-Padieu E. 2001. Phytoplasmes et phytoplasmoses: caractéristiques, symptômes et diagnostic. Cahiers Agriculture, 10: 361-376.

De Francqueville de H, Taffin de G, Sangaré A, Saint JP, Pomier, Renard JP. 1989. Mise en évidence de caractères de tolérance au Phytophthora heveae chez le cocotier en Côte d'Ivoire. Oléagineux, 44(2): 93-100.

Dery KS, Philippe R, Mariau D, 1996. Auchenorryncha (Homoptera), suspected vectors of coconut lethal yellowing disease in Ghana. Plantations, 3(5): 355363.

Dollet M, Macome F, Vaz A, Fabre S. 2011. Phytoplasmas identical to coconut lethal yellowing phytoplasmas from Zambesia (Mozambique) found in a pentatomide bug in Cabo Delgado province. Bulletin of Insectology, 64(Suppl): S139-S140.

Dollet M, Quaicoe R, Pilet F. 2009. Review of coconut "Lethal Yellowing" type diseases. Diversity, variability and diagnosis. Oléagineux Corps Gras Lipides, 16(2): 97-101.

Dollet M, Saillard C, Garcia Jurado O, Vignault JC, Gargani D, Tully JG, Bové JM. 1980. Approche de l'étude 
sérologique des mycoplasmes du jaunissement mortel des cocotiers en Afrique de l'Ouest. Oléagineux, 35(6): 299.

Dollet M. 1978. Compte rendu de la 3ème réunion de «1'international Council on lethal yellowing ». Oléagineux, 33(4): 165-170.

Dollet M, Giannotti J, Renard JL, Ghooh SK. 1977. Etude du jaunissement létal du cocotier au Cameroun: la maladie de Kribi; observations d'organismes de types mycoplasmes. Oléagineux, 32(7): 317322.

Dollet M, Giannotti J. 1976. Maladie de kaincope: présence de mycoplasme dans le phloème de cocotiers malades. Oléagineux, 31(4): 169-170.

Ennin Stella A, Banful, Andoh-mensah E, Issaka RN, Lamptey JN, Dzomeku BM, Manu JA, Bolfrey-arku Grace. 2008. Des Cultures Vivrières en Association avec le Cocotier: une Alternative pour replanter des cocotiers hybrides tolérants ou résistants au Jaunissement Mortel au Ghana. Atelier international sur les jaunissements mortels du cocotier, Accra, Ghana.

Eziashi E, Omamor I. 2010. Lethal yellowing disease of the coconut palms (Cocos nucifera L.): An overview of the crises. African Journal of Biotechnology, 9(54): 9122-9127.

Mariau D, Dery SK, Sangaré A, N'cho Yavo P, Philippe R. 1996. Le jaunissement mortel du cocotier au Ghana et tolérance $\mathrm{du}$ matériel végétal. Plantations Recherche Développement, 3(2): 105110.

McCoy RE. 1982. Antibiotic treatment for control of tree diseases associated with mycoplasma-like organism. Reviews of Infectious Diseases, 4: 157-161.

McCoy RE. 1978. Accumulation de résidu d'antibiotique dans les noix de cocotier traitées à l'antibiotique pour lutter contre le jaunissement mortel. Oléagineux, 31(5): 215-218.

McCoy RE. 1974. How to treat your palm with antibiotic. University of Florida, Agriculture Expt. Station Circ. s. 228, 7 p.

Molard RD, Chagnier B. 1989. Ecophysiologie des moisissures des produits alimentaires. Compte rendu intégral de la session AFTAA, Paris, p. 711.

Myrie W, Brown S, Been Basil O, Douglas L, Mclaughin W. 2008. Revue sur les insectes vecteurs des phytoplasmes associés au jaunissement mortel du cocotier en Jamaïque. Atelier international sur les jaunissements mortels du cocotier, Accra, Ghana.

Myrie W, Paulraj L, Dollet M, Wray D, Been Basil O, Mclaughin W. 2006. First report of lethal yellowing disease of coconut palms caused by phytoplasma on Nevis Island. Plant Disease, 90(6): 834.

Nejat N, Sijam K, Abdullah SNA, Vadamalai G, Dickinson M. 2009. Phytoplasmas associated with disease of coconut in Malaysia: phylogenetic groups and host plant species. Plant Pathology, 58(6): 1151-1160.

Philippe R, Reignard S, Deschamps S, Nkansah Poku J, Quaicoe R, Pilet F, Fabre S, Dollet M. 2009. Study on the transmission of coconut lethal yellowing in Ghana. Oléagineux, Corps Gras, Lipids, 16: 102-106.

Philippe R, Reignard S, Deschamps S, Nkansa Poku J, Pilet F, Fabre S, Dollet M. 2008. La recherché des insectes vecteurs du jaunissement mortel du cocotier au Ghana. Atelier international sur les jaunissements mortels du cocotier, AccraGhana.

Pilet F, Philippe R, Reignard S, Deschamps S, Quaicoe R, Nkansa, Poku J, Fabu S, Dollet M. 2008. Identification d'insectes vecteurs 'potentiels' du Cape Saint Paul wilt sur le cocotier au Ghana par PCR. 
Atelier sur le jaunissement mortel du cocotier, Accra-Ghana.

Philippe R, Nkansah Poku J, Fabre S, Quaicoe R, Pilet F, Dollet M. 2007. Search for the vector of Cape Saint Paul wilt (coconut lethal yellowing) in Ghana. Bull. Insectol. 60: 179-180.

Pohé J. 1996. Contribution à l'étude de la pourriture du coeur et de la chute des noix immatures du cocotier dues à Phytophthora katsurae (Ko et Chang) en Côte d'Ivoire. Thèse de Doctorat présentée à l'Institut National d' Agronomique Paris-Grignon, France, 176 p.

Sangaré A, Taffin de G, Francqueville de H, Arkurst ED, Pomier M. 1992. Le jaunissement mortel du cocotier au Ghana: premiers résultats sur le comportement au champ du matériel végétal. Oléagineux, 47(12): 699-704.

Taffin de G, Sangaré A. 1989. Intérêt du cocotier en Afrique de l'Ouest. Oléagineux, 144(12): 285-291.
Taffin de G, Roggnon F. 1991. Le diagnostic foliaire du cocotier, pratique agricole ; conseil de l'IRHO N³18. Oléagineux, 46(4): 169-171.

Warwick Dulce RN, Passos Edson EM. 2009. Outbreak of stem bleeding in coconuts caused by Thielaviopsis paradoxa in Sergipe, Brazil. Tropical Plant Pathology, 34(3): 175-177.

Warwick DRN, Bezerra APO, Renard JL. 1991. Le comportement des cocotiers hybrides à l'égard du leaf blight dû à $B$. theobromae Pat. Observations au champ. Oléagineux, 46(3): 100-108.

Yao AA. 1997. Contribution à l'étude du dépérissement mortel du cocotier dans la cocoteraie industrielle de Grand-Lahou (SICOR). Mémoire de fin d'études, option défense des cultures pour l'obtention du diplôme d'agronomie approfondie (DAA). Institut National Polytechnique Félix Houphouet-BoignyEcole Supérieure Agronomique, Côte d'Ivoire, $71 \mathrm{p}$. 